\title{
3D FINITE ELEMENT ANALYSIS IN THE SELECTIVE LASER MELTING PROCESS
}

\author{
Contuzzi, N.; Campanelli, S. L. \& Ludovico, A. D. \\ Polytechnic of Bari, Department of Management and Mechanical Engineering, Viale Japigia, 182, \\ 70126 Bari, Italy \\ E-Mail: n.contuzzi@poliba.it; campanel@poliba.it; ludovico@poliba.it
}

\begin{abstract}
Selective Laser Melting (SLM) is actually the most attractive technique in an Additive Manufacturing (AM) technology because of the possibility to build layer by layer up nearly full density metallic components without needing for post-processing. One of the main problems in SLM processes is represented by the thermal distortion of the model during forming; the part tends to be deformed and cracked due to the thermal stress. Therefore, it is important to know the effect of the process parameters on the molten zone and consequently on the density of the consolidated material. Great advantage can be obtained from the prediction of temperature evolution and distribution.

The aim of this study is to evaluate the influence of the process parameters on the temperature evolution in a 3D model. The developed code evaluates the distribution and evolution of the temperatures in the SLM process and simulates the powder-liquid-solid change by means of a check of the nodes temperature.

(Received in June 2010, accepted in June 2011. This paper was with the authors 1 month for 1 revision.)
\end{abstract}

Key Words: Rapid Prototyping, Selective Laser Melting, FEM, Metal Powders

\section{INTRODUCTION}

Selective Laser Sintering (SLS) was developed by Carl Deckard at the University of Texas at Austin, USA in 1987 for making plastic prototypes. In 1992, DTM Corporation (Texas, USA) introduced the Sinterstation ${ }^{\mathrm{TM}}$ machine for SLS [1]. Later on it also became a common technology to produce products for long-term use. The success of SLS as rapid prototyping and rapid manufacturing technology mainly results from the ability to process almost any type of material.

Recently, the interest in SLS is mainly focused into metals because of the possibility of building metal parts of complex geometries that can be used not only for the prototyping step but also for a small series [2, 3]. This aspect is mainly attractive in aerospace, automotive, electronics and biomedical industries, as well as many others technological fields.

Driven by the need to process nearly full dense objects, with mechanical properties comparable to those of bulk materials and by the desire to avoid lengthy post processing cycles, SLM has been developed. Polymers as well as metals can be completely molten by a laser beam, however the appellation Selective Laser Melting is reserved for metallic materials. In SLM nearly full density parts can be produced without needing for postprocessing steps, while the same materials can be used as in serial production. In order to reach a high density, the metallic powder particles are fully molten.

Basically, the SLM process is the same as SLS: the difference between them consists in the full melting of powders in the first one and in the partial melting in the second one. Thus, SLM involves higher laser energy densities than SLS. One of the serious problems in SLM processes using metallic powders is the thermal distortion of the model during forming [4]. 
Since the solidified part is cooled rapidly, the workpiece tends to be deformed and cracked due to thermal stress. The numerical simulation can provide useful information for SLM process design, because the designer can optimize the laser strategy to improve the workpiece quality.

Since the process is governed by non-linear phenomena due to both material evolution and non-linearity of material properties, the estimation for the workpiece building evolution is very complex. Recent literature reports several papers on numerical modelling of SLS and SLM processes, but in most works the analysis is usually limited to one or two space dimensions [5]. For example, Matsumoto [6] proposed a single layer model subjected to plane stress deformation with a 2D FE method that combined heat conduction and elastic deformation. Mori [7] proposed a viscoplastic analysis for simulating macroscopic deformation in powder forming process and he also analyzed the microscopic on the scale of the powder scale. A microscopic approach was also used by Shiomi [8] who analyzed the shape evolution of melted part of the powders into a sphere due to the surface tension. Patil and Yadava [9] proposed a two-dimensional finite element model to predict the temperature on the powder bad surface, considering the effective thermal conductivity that evolves with the temperature, and a constant density. Chen and Zhang [10] proposed a three-dimensional thermal modelling for the sintering of two component metal powder with different melting temperatures. Dong et al. [11] developed a three-dimensional finite element model to predict temperature and density distribution in sintered amorphous polymer powders. The model takes in account the laser beam velocity, laser power, laser diameter and the preheating temperature. At present only some published works allow the material evolution [1] in a complex multilayer 3D model with complete melting, this is why the aim of this paper is to analyze a thermal 3D multilayer model that evaluates the material evolution and consequently its non-linearities.

The aim of this study was to evaluate the influence of the process parameters on the temperature evolution in a 3D model. The developed code evaluates the distribution and evolution of the temperatures in a SLM process and simulates the powder-liquid-solid change, by means of a check of the nodes temperature. The material considered in this study is a powder of stainless steel AISI 316L that is fully molten during the SLM process.

\section{THE PROCESS OF SELECTIVE LASER MELTING}

\subsection{The process}

SLM is very similar to SLS as both are based on the same concept; the only difference is represented by the partial melting of the powder in SLS and full melting in SLM [4].

The SLM process uses data from a 3D CAD-file and transfers the sliced data to a computer-controlled laser device, which fuses successive layers of powder to create a 3D product. Fig. 1 schematically shows the SLM process: the powder is spread by a roller over the surface of a build cylinder. The piston in the cylinder moves down one object layer thickness (LT) to accommodate the new layer of powder. The powder cartridge moves incrementally upward to supply the desired quantity of powder. A laser beam is then traced over the powder surface to selectively melt and bond it to the underlying layers. The process is repeated until the entire object is fabricated. Since the powder is fully molten in the SLM process, protection of the SLM part from oxidation is essential; therefore, the chamber works under an inert atmosphere of $\mathrm{Ar}$ or $\mathrm{N}_{2}$ depending on the processed materials. 


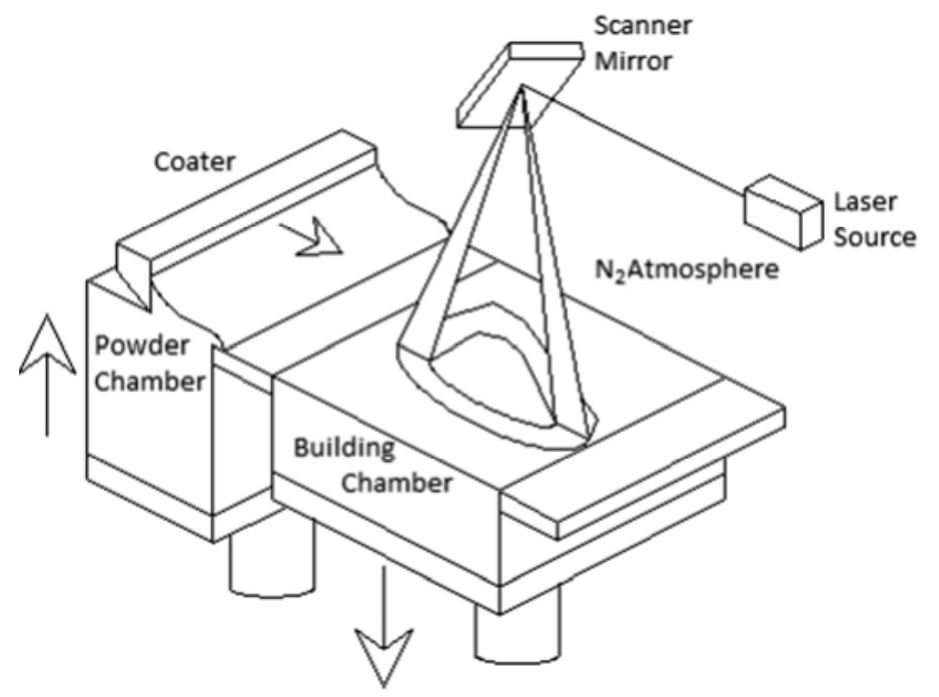

Figure 1: Schematic drawing of SLS process.

\subsection{SLM process parameters}

In SLM, there are a number of input parameters that can be controlled and varied in order to get sintered parts with optimized quality. Some of these parameters are layer thickness, scan speed, scan spacing, powder characteristics (size, distribution, shape, etc.) and laser parameters (power, spot size, etc.) [12].

In particular, the success of a product manufactured with the SLM process requires a thorough control of the parameters which influence the melting and the amount of energy density involved in the process.

The energy density $E_{d}$ can be calculated by means of the Eq. (1) where $P$ is the incident laser power $[\mathrm{W}], v_{s}$ is the laser scanning speed [mm/s] and $d$ is the laser beam spot diameter [mm] [4].

$$
E_{d}=\frac{P}{v_{s} \times d}\left[\frac{\mathrm{J}}{\mathrm{mm}^{2}}\right]
$$

\section{MODELLING APPROACH}

In this work a 3D FE model with complete melting was developed.

Preliminary experimental tests were conducted to determine the profile dimensions of the molten-resolidified zone in SLM parts. The apparatus used for experiments was equipped with a Nd:YAG laser, operating in continuous wave (CW), with a maximum power of $100 \mathrm{~W}$ and a laser spot diameter of $0.2 \mathrm{~mm}$. Moreover the laser was characterized by a Gaussian power density distribution. The material processed consisted in powders of AISI 316L steel with an average size of $40 \mu \mathrm{m}$. The laser power $P$, the layer thickness $L_{t}$ and the scanning velocity $v_{s}$ were kept constant and set respectively to $100 \mathrm{~W}, 30 \mu \mathrm{m}$ and $450 \mathrm{~mm} / \mathrm{s}$. Built parts were sectioned and analysed by an optical microscope. Figs. 2a and $2 \mathrm{~b}$ show two micrographs of a section of an AISI 316L SLM part with a magnification of $400 \times$. It is evident that the metal powder is completely fused and constituted by molten/re-solidified zones with curved edges (approximately parabolic). The width $(w)$ and the depth $(d p)$ of a single solidified track were measured (Fig. 2b).

These dimensions were used to calibrate the 3D FE model. The geometry considered for the 3D FE analysis was characterized by three powder layers $(6 \times 9 \times 0.3 \mathrm{~mm})$ and a larger layer $(6 \times 9 \times 1 \mathrm{~mm}$ ) below (Fig. 3); this model allowed neglecting the transient effects. 

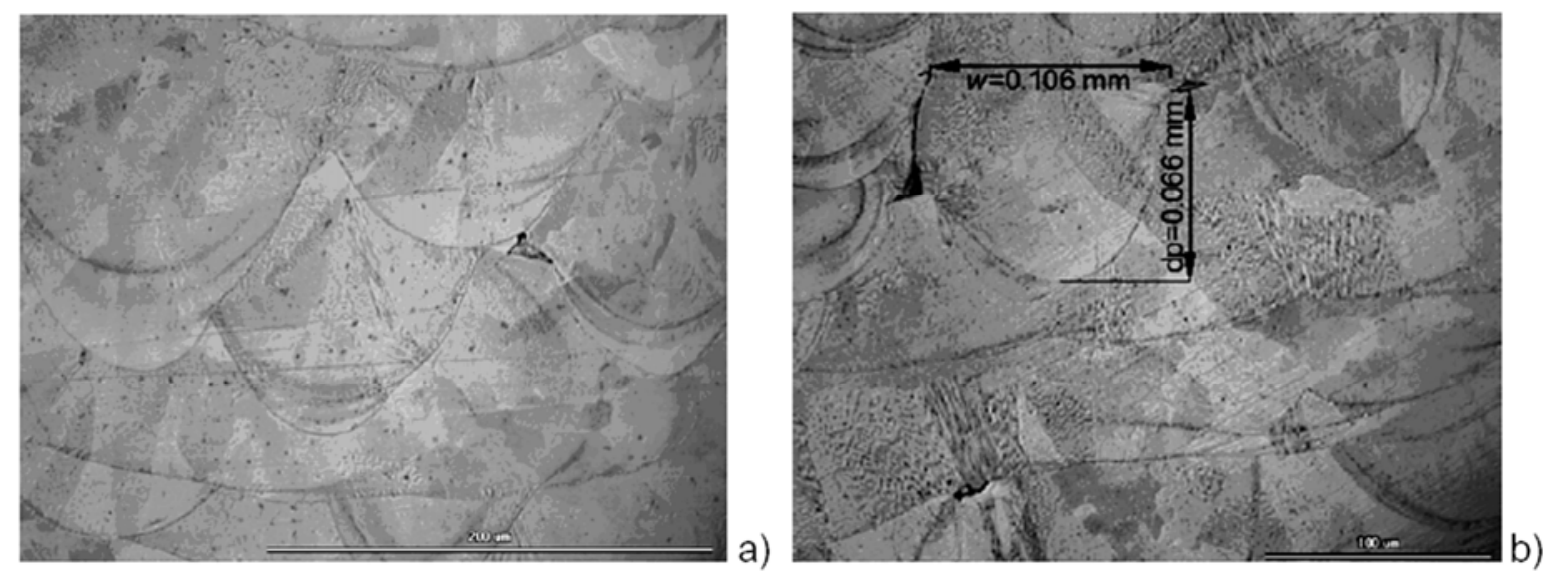

Figure 2: Optical micrographs of a specimen built in AISI 316L (400× magnification)

The lower layer was constituted in the central part by solid material (that represents the previous layers, where the laser beam is already passed), while in the lateral part by powders (Fig. 4). The powder is indicated in dark grey (zone B) and the solid material in light grey (zone A).
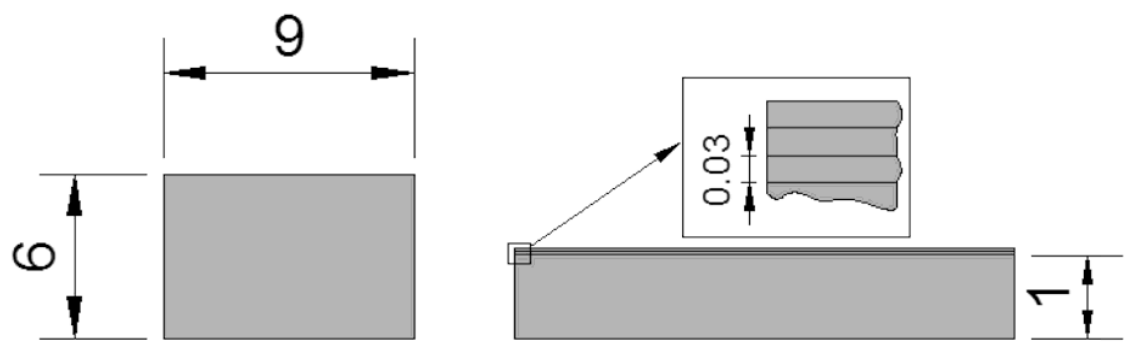

Figure 3: Geometry.

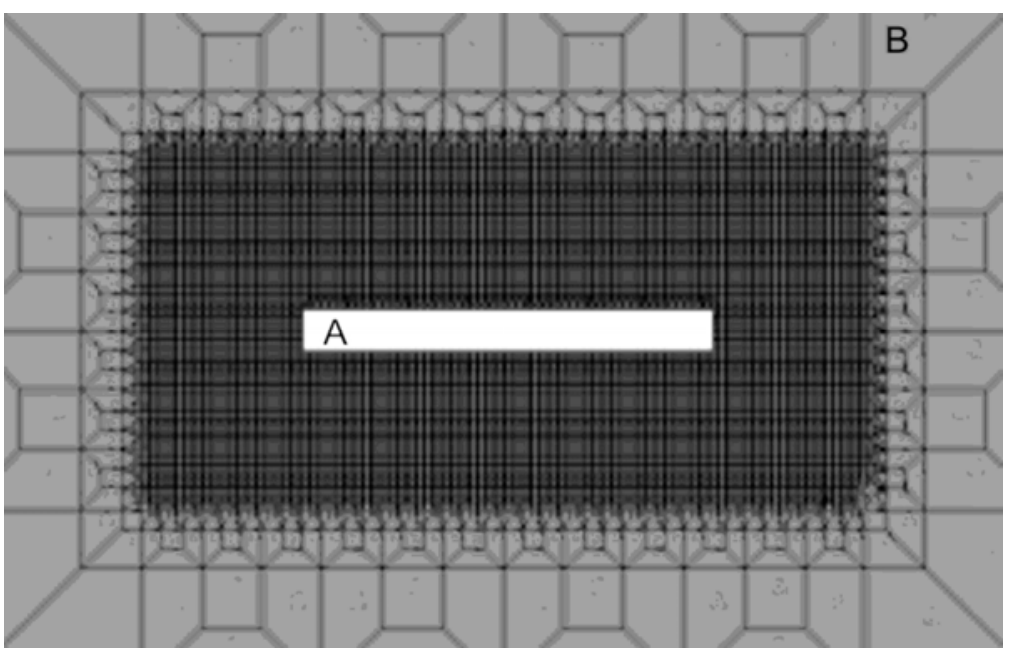

Figure 4: Drawing of the bottom layer.

A very fine mesh was used in the central part, where the powder is molten by the heat source, while a coarse mesh was adopted in the external part (Fig. 5), where the thermal gradients are supposed to be very low. The fine cells are $0.056 \mathrm{~mm}$ large.

All the external faces have a natural convection boundary condition with zero heat flux except the bottom and lateral faces and the external temperature is supposed to be $22^{\circ} \mathrm{C}$. 
The laser heat input was modelled by an internal heat source, as was demonstrated by Kossolov et al. [5].

The laser used for experiments has a Gaussian power density distribution; in the simulation modelling, due to the very small size of the finite elements, the power density was considered constant. Moreover, the laser operates in continuous wave mode $(\mathrm{CW})$ and the laser path is shown in Fig. 6b. The laser beam is assumed to irradiate five elements as shown in Fig. 6a.

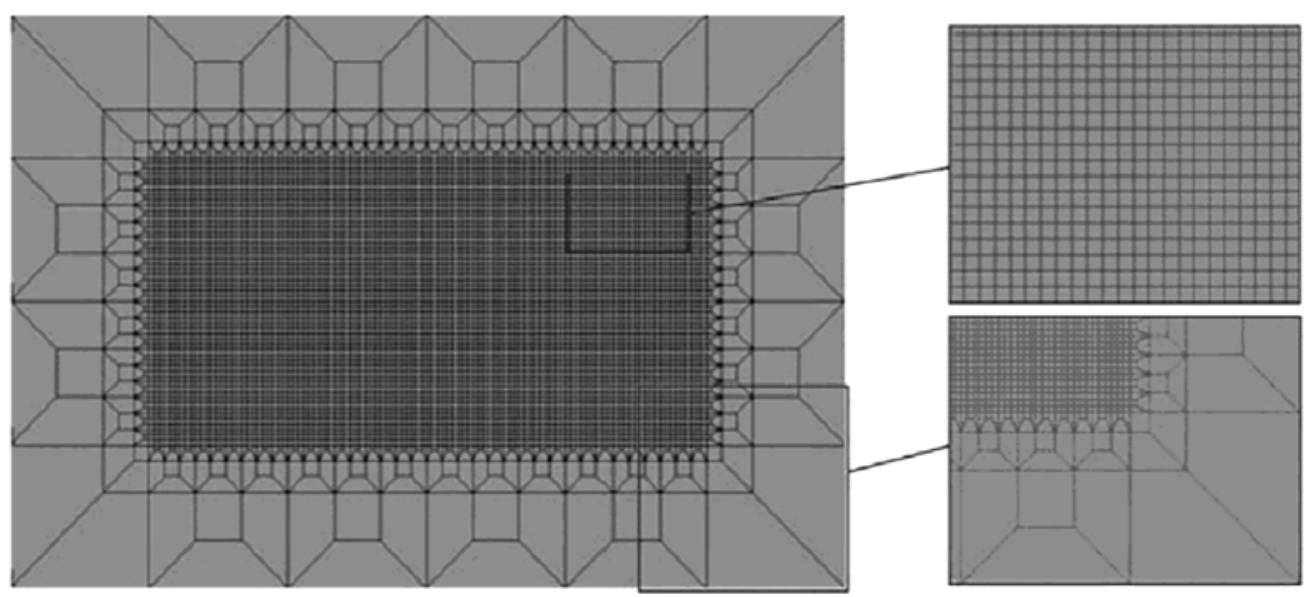

Figure 5: Mesh strategy.

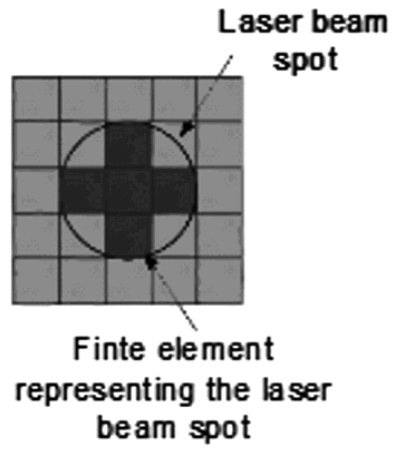

a)

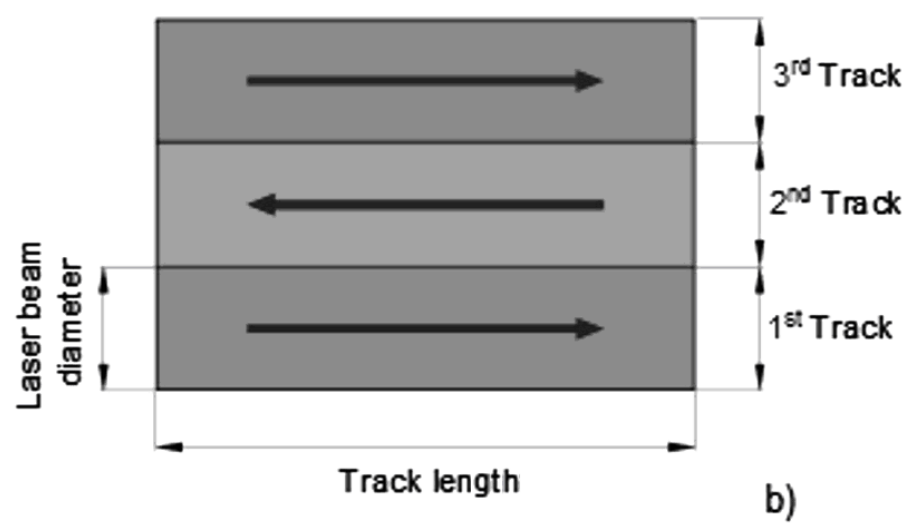

Figure 6: a) laser spot; b) laser path.

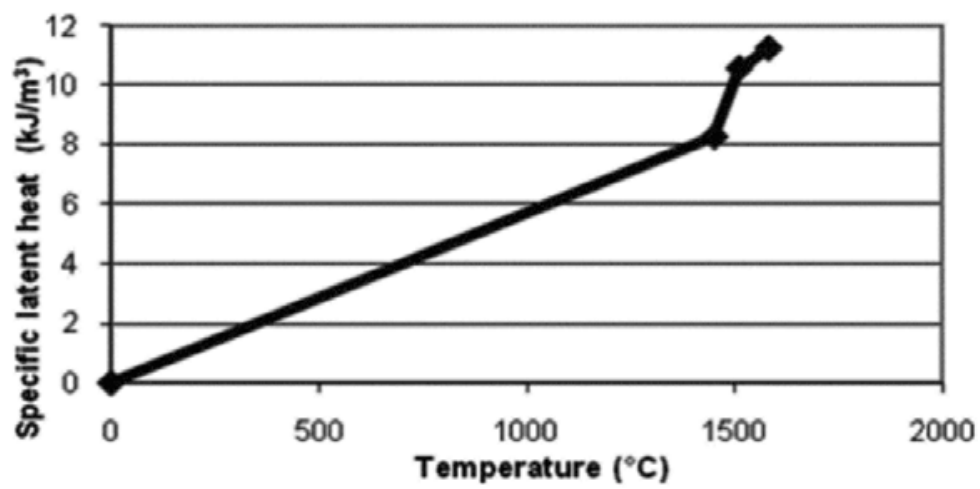

Figure 7: Specific latent heat.

Since the used FE software (Ansys ${ }^{\circledR}$ ) does not support the powder-solid change, a subroutine was developed to simulate this change, through the evolution from a powder to a 
solid material, when the temperature is greater than the melting point $\left(T_{m}\right)$. This is due to the modelling of two different materials: the powder and the solid. Moreover, the workpiece structure can evolve with time describing the non-linear effect of sintering.

The thermal properties of the elements are given in correspondence with the state of the elements: powder or solid, while the molten liquid phase is considered introducing the specific latent heat in the material properties (Fig. 7).

Table I: Materials properties.

\begin{tabular}{|l|c|}
\hline \multicolumn{2}{|l|}{ POWDER THERMAL PROPERTIES } \\
\hline Density $\left[\mathrm{kg} / \mathrm{m}^{3}\right]$ & 4182 \\
\hline Conductivity $[\mathrm{W} / \mathrm{m} \cdot \mathrm{K}]$ & 1.67 \\
\hline Specific heat $[\mathrm{J} / \mathrm{kg} \mathrm{K}]$ & 500 \\
\hline SOLID THERMAL PROPERTIES \\
\hline Density $\left[\mathrm{kg} / \mathrm{m}^{3}\right]$ & 8200 \\
\hline Conductivity $[\mathrm{W} / \mathrm{m} \cdot \mathrm{K}]$ & 16.2 \\
\hline Specific heat $[\mathrm{J} / \mathrm{kg} \mathrm{K}]$ & 500 \\
\hline
\end{tabular}

The "phase" change from solid to powder was obtained through a control on nodal temperature and this is explained on the flow chart in Fig. 8.

The subroutine is divided in four different steps:

1. Moving of the heat source on the powder layer;

2. Element scanning;

3. Nodal scanning;

4. Computation of average nodal temperature.

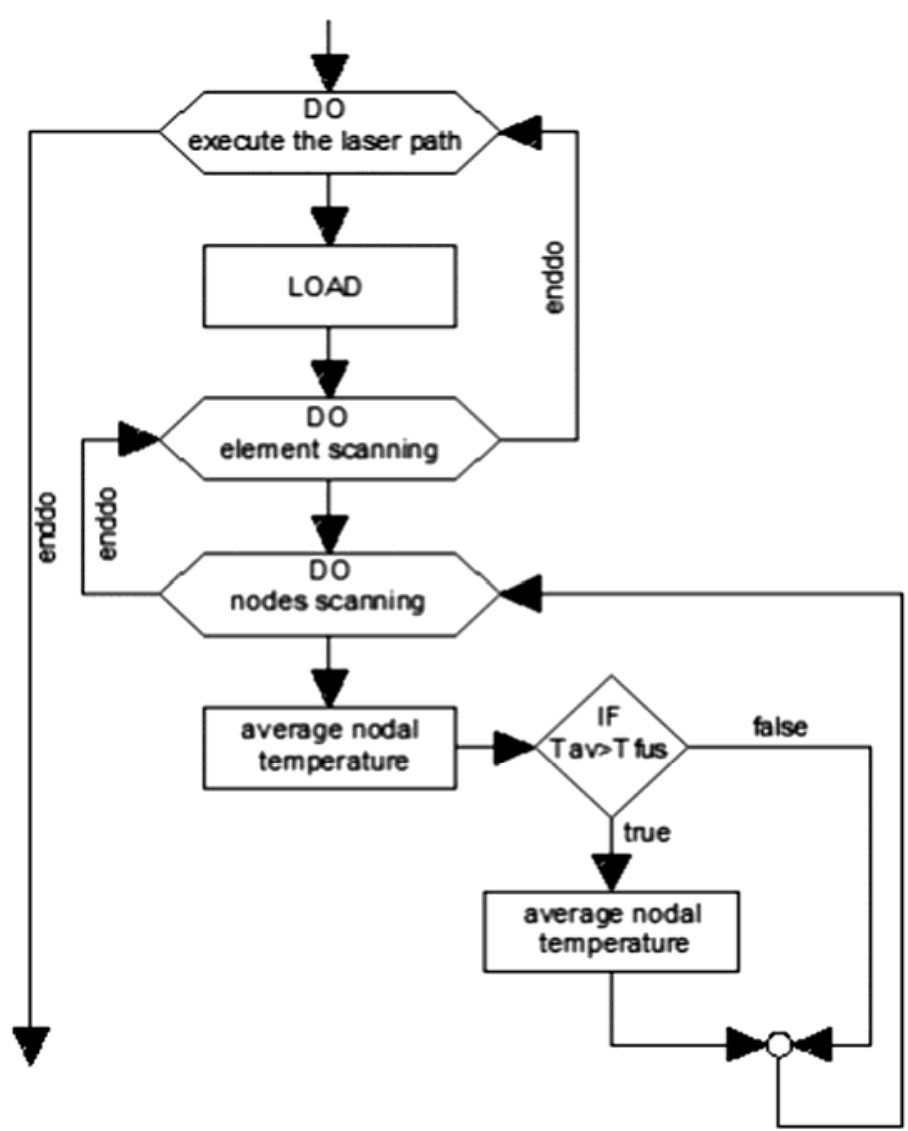

Figure 8: Flow chart for checking the temperature. 
The heat source moves in discrete way and for every load step, all the elements are selected. For every element the subroutine checks the number of nodes and stores their temperature. Average nodal temperature $\left(T_{a v}\right)$ is calculated; if $T_{a v}>T_{m}$, the subroutine changes the element material properties from powder to solid. Material properties of AISI 316L steel are reported in Table I.

\section{RESULTS AND DISCUSSION}

Figs. 9a and 9b show the temperature profiles predicted by simulation at the end of the third scan for the first and the second molten layer. The Zone 1 and the Zone 2 in figure indicates the nodes that have a temperature greater than the molten one, and therefore indicates the molten/solid transformation. For the first layer, the prediction for the maximum value of the temperature, under the laser beam, is $1532^{\circ} \mathrm{C}$, while for the second layer is $1491^{\circ} \mathrm{C}$, this is due to an higher solid material thickness, that increases the heat loss in the bulk.

The solid material elements are shown in the black box in the central part of the body.

Fig. 9c shows the profile at the end of the third scan for the third layer, the prediction for the maximum value of temperature is $1471^{\circ} \mathrm{C}$ (Zone 3).

Fig. 10 shows the temperature of nodes on every layer. The nodes in gray, on the first layer, for three times reach the molten temperature; the thermal input is chosen in such a way that it melts three powder layers, for this reason there is a heat treatment in the layers below. On the austenitic steel, like AISI 316L, it has a minor importance, but on other steels it can have very positive effects. The action of the heat treatment on the last layer can be obtained with defocusing laser beam.

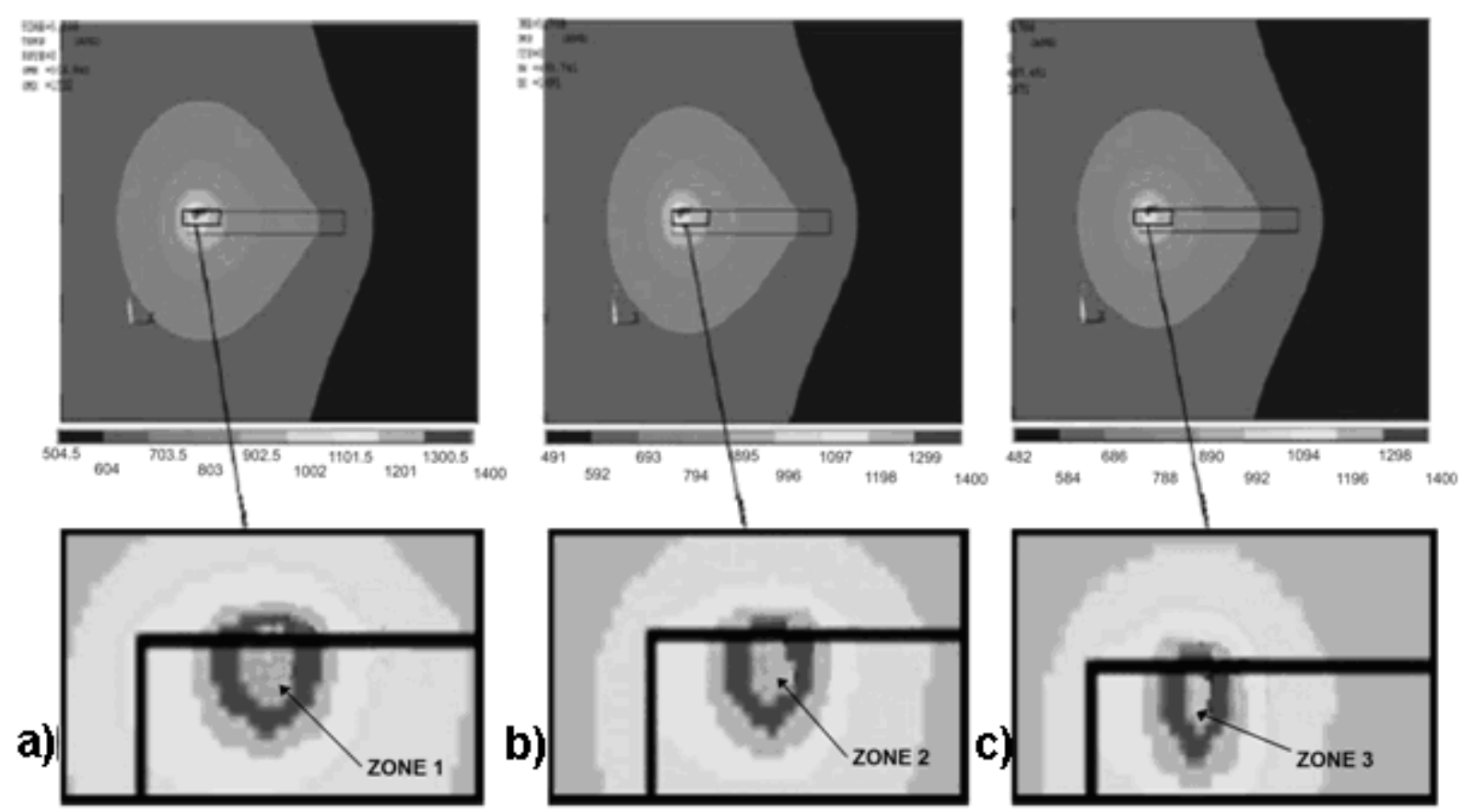

Figure 9: Temperature distribution for: a) first layer; b) second layer; c) third layer.

Fig. 10 shows the molten zone in the simulated model.

When the temperature exceeds the threshold of $1400^{\circ} \mathrm{C}$, there is the change of materials and the conductivity grows quickly; this can be seen from the shape of the isothermal lines in the central part of the body. The temperatures also change with depth from $936^{\circ} \mathrm{C}$ at the bottom to $1471^{\circ} \mathrm{C}$ under the laser beam, after the deposition of the third layer. 


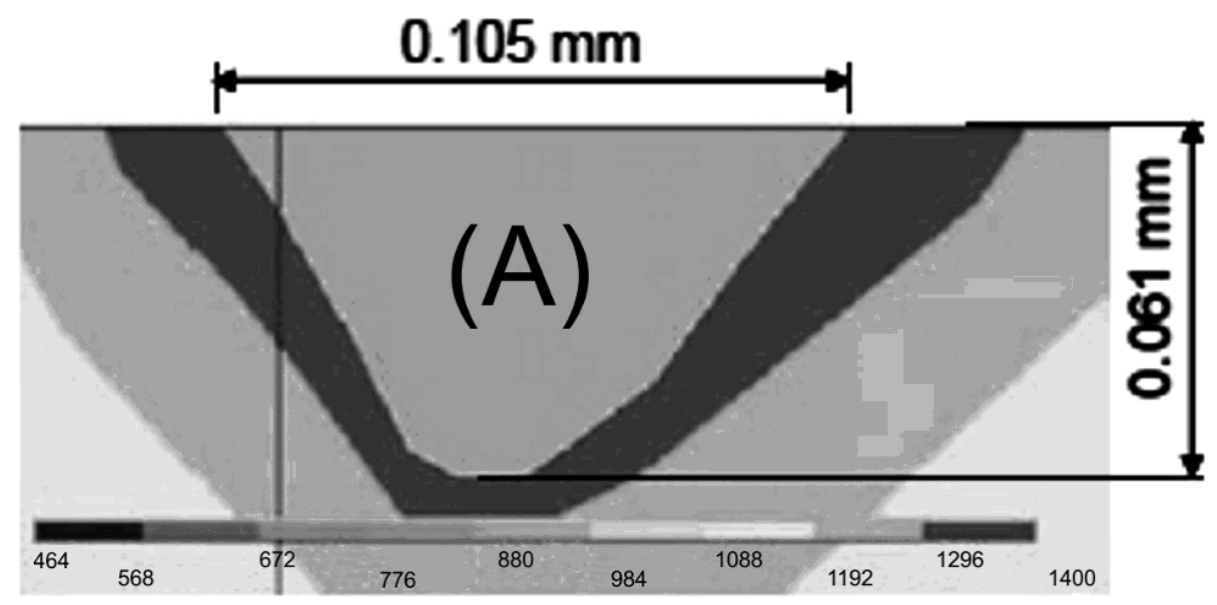

Figure 10: Micrograph of an SLM part in AISI 316L.

Fig. 10 shows the result for the molten/resolidified zone coming from the FE simulation. Dimensions of the molten/resolidified zone coming form experimental tests were compared with those coming form the 3D FE analysis. The mean error for depth is around $7.5 \%$, while for width it approaches $1 \%$.

The dimensional error on the molten zone depends from the different effects of thermal inertia and different heat loss. Instead, the difference on the isothermal is probably due to the different heat loss on every layer, considering that, the laser power is supposed constant on the three layers, thus the solid part is equal on every layer.

\section{CONCLUSIONS}

In this work a FE simulation of the laser melting process has been performed. The developed code is able to evaluate the distribution and the evolution of the temperatures in the SLM process and simulates the powder-liquid-solid change by means of a check of the nodes temperature. The model has been calibrated with a micrograph of part built in stainless steel AISI 316L with a machine equipped with a Nd:YAG laser of maximum power of $100 \mathrm{~W}$. The results of the simulation show a good agreement with the real dimension of the melted/resolidified zone. This model can be improved performing a mechanical analysis in order to predict stress and strain fields and to determinate residual stresses. The model may represent a useful instrument to optimize the process parameters, to estimate the adhesion between the layers, and to characterize the best building strategy. A further step will be to implement a thermo-mechanical model to estimate the residual stresses and, therefore, the strains developed during the process.

\section{REFERENCES}

[1] Kruth, J. P.; Mercelis, P.; Van Vaerenbergh, J.; Froyen, L.; Rombouts, M.; Lowers, B. (2004). Selective laser melting of iron-based powder, Journal of Materials Processing Technology, Vol. 149, No. 1-3, 616-622, doi:10.1016/j.jmatprotec.2003.11.051

[2] Kruth, J. P.; Mercelis, P.; Van Vaerenbergh, J.; Froyen, L.; Rombouts, M. (2003). Advances in Selective Laser Sintering, Proceedings of International Conference on Advanced Research in Virtual and Rapid Prototyping, 59-70

[3] Bourell, D. L.; Marcus, H. L.; Barlow, J. W.; Beaman, J. J. (1992). Selective laser sintering of metals and ceramics, International Journal of Powder Metallurgy, Vol. 28, No. 4, 369-381 
[4] Lu, L.; Fuh, J. Y. H.; Wong, Y. S. (2001). Laser-Induced materials and processes for rapid prototyping, Kluwer Academic Publishers, Boston, doi:10.1007/978-1-4615-1469-5

[5] Kolossov, S.; Boilatt, E.; Glardon, R.; Fisher, P.; Locher, M. (2004). 3D FE simulation for temperature evolution in the selective laser sintering process, International Journal of Machine Tools \& Manufacture, Vol. 44, No. 2-3, 117-123, doi:10.1016/j.ijmachtools.2003.10.019

[6] Matsumoto, M.; Shiomi, M.; Osakada, K.; Abe, F. (2002). Finite element analysis of single layer forming of metallic powder bed in rapid prototyping by selective laser processing, International Journal of Machine Tools \& Manufacture, Vol. 42, No. 1, 61-67, doi:10.1016/S08906955(01)00093-1

[7] Mori, K. (2006). Finite element simulation of powder forming and sintering, Computer methods in applied mechanics and engineering, Vol. 195, No. 48-49, 6737-6794, doi:10.1016/j.cma.2005.10.015

[8] Shiomi, M.; Yoshidome, A.; Abe, F.; Osakada, K. (1999). Finite element analysis of melting and solidifying processes in laser rapid prototyping of metallic powder, International Journal of Machine Tools \& Manufacture, Vol. 39, No. 2, 237-252, doi:10.1016/S0890-6955(98)00036-4

[9] Patil, R. B., Yadava, V. (2007). Finite element analysis of temperature distribution in single metallic powder layer during metal laser sintering, International Journal of Machine Tools \& Manufacture, Vol. 47, No. 7-8, 1069-1080, doi:10.1016/j.ijmachtools.2006.09.025

[10] Chen, T. B., Zhang, Y. W. (2007). Thermal modelling of laser sintering of two-component metal powder on top of sintered layers via multi-line scanning, Appl. Phys. A, Vol. 86, No. 2, 213-220, doi:10.1007/s00339-006-3739-1

[11] Dong, L., Makradi, A., Ahzi, S., Remond, Y. (2009). Three-dimensional transient finite element analysis of the selective laser sintering process, Journal of materials processing technology, Vol. 209, No. 2, 700-706, doi:10.1016/j.jmatprotec.2008.02.040

[12] Kruth, J. P; Ludovico, A. D.; Campanelli, S. L.; Rombouts, M.; Van Vaerenbergh, J. (2004). Statistical optimisation of selective laser sintering of metal powders, Proceedings of $4^{\text {th }}$ Intelligent Computation in Manufacturing Engineering, 643-647 